\title{
Establishing Partnerships To Provide Health Education In Appalachian Schools: An Approach To Service Learning
}

\author{
Lisa Kauffman-Craig, Bay Community College, USA \\ Charlotte McManus, Ohio University Chillicothe, USA \\ Vicky K. Parker, Ohio University Chillicothe, USA
}

\begin{abstract}
Service learning is a form of collaboration between an educational facility and a community agency. The concept of service learning is an innovative teaching method designed to benefit both collaborating partners through respect of each other's knowledge, expertise and skills. Needs and goals of both partners are met through many different types of service learning projects. Examples of such projects in which the OUC nursing program has participated include health fairs in the middle and high school populations, health education in elementary classrooms, health fairs in local industry, and working with the elderly in the community.

The Ohio University-Chillicothe Nursing Program, located in a section of Ohio know as Appalachia, believes in the concept of service learning to promote health and well-being in the community. Health care in the Appalachian area, particularly health promotion and disease prevention, is a challenge to health care providers as residents in this area have a fatalistic view of health - "what will be, will be". Service learning projects are an excellent way to provide health promotion education to those who may not seek this out on their own.

The collaborations formed between agencies and the nursing program benefit both partners. The nursing students are exposed to the health care beliefs and need of Appalachia on a first-hand basis through an innovative approach in clinical education. Community agencies benefit by being able to expand the amount of health education they can offer which increases their manpower with use of the students.
\end{abstract}

Keywords: Service Leaning; Collaboration; Partnerships

\section{INTRODUCTION}

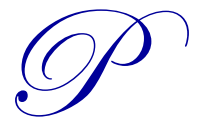

reparing students for the challenges of tomorrow and providing service to Chillicothe and the surrounding region is the mission of Ohio-University Chillicothe (Ohio University-Chillicothe, 2014). This paper describes how nursing faculty have established a partnership with Vinton County schools to provide a service of health education to the elementary school children of their community. In providing this service, nursing students are applying the didactic content of teaching-learning principles in a "real-life" situation as opposed to a fabricated situation in the classroom. The benefits of collaboration to both partners (OUC and Vinton County Schools) are explained, as well as the development and implementation of this project. Evaluation by both nursing students and those involved with the community schools are shared showing the overwhelming evidence that supports the use of partnerships in higher education.

\section{BACKGROUND}

As we all know, health care is constantly changing. The medications and treatment of illness used yesterday are not the same as those used today. Thus, a major responsibility of nurses today is the education of 
patients, whether that education is related to understanding their disease process or learning what to expect when returning to their room after a surgical procedure. Studying the principles of teaching-learning is necessary in an Associate Degree and Baccalaureate Degree nursing curriculum. The graduate must be able to teach their patients, thus meeting the demands of a dynamic health care system.

A traditional teaching method used by nursing faculty to emphasize the didactic content relating to teaching-learning principles has been to role play in the classroom. Nursing students were typically placed in small groups and assigned a specific teaching scenario, such as "Hygiene, Nutrition/Exercise, Dental, Fire and Gun Safety, and Bullying/Conflict Management". The group would have 15-20 minutes (depending on class size) to present this information to the elementary students, and faculty would evaluate their performance. Faculty were finding it difficult to fairly evaluate students' learning of the principles for several reasons: 1) In a group, it is more difficult to evaluate each student's learning; 2) The short presentation time is not adequate to effectively evaluate such an important nursing principle; and 3) The classroom setting does not compare to a "real-life" situation. Thus, faculty began searching for an alternative project that would better allow the students to apply teaching-learning principles and for faculty to evaluate the students' learning of these principles.

\section{Partnerships And Service Learning}

Establishments of higher learning are promoting collaboration, partnerships and service learning, not only from an economic perspective, but also for community recognition. Regional campuses and community colleges have a mission to provide services to the surrounding community. Service learning is a form of collaboration between partners who are willing to share knowledge, expertise, and skills that result in positive outcomes for each.

The American Association of Community Colleges (AACC) (2010), explains how service learning combines community service with classroom instruction, engaging the student in activities that address community needs while developing their critical thinking and academic skills. A project known as Community Colleges Broadening Horizons through Service Learning 2009-2012, administered by the AACC, establishes partnerships between eight selected mentor colleges and community agencies, among those being K-12 schools. AACC notes that these service learning opportunities not only are meaningful experiences for both the college student and the participating partner, but also build deeper, long-term faculty/partner relationships (AACC, 2010).

Service learning is a teaching strategy that fosters learning and reflection combined with meaningful community experiences within an academic setting (Balakas \& Sparks, 2010). This approach of service learning seemed to be the perfect match for implementing teaching-learning strategies for our nursing students.

\section{Partnering With Rural Appalachian Schools}

Ohio University-Chillicothe lies on the edge of Appalachia. The Appalachian area was developed by the Appalachian Regional Commission in 1965 due to the geographical make-up of the area and their economic needs. The geographical area, associated with the rugged ridges and remote valleys of the Appalachian Mountains, corresponds to isolation and seclusion in small rural communities (Denham, Meyer, Toborg \& Mande, 2004). These factors, as well as the poverty levels in these areas, translate into decreased accessibility to health services and decreased providers of health care services.

Researchers who have studied Appalachia have argued that beliefs and practices rooted in culture have an impact on health promotion and disease prevention (Denham, Meyer, Toborg, \& Mande, 2004). A common belief in the Appalachian culture that makes health education difficult is that of fatalism, or "what will be, will be". This concept is passed down from generation to generation, as residents in Appalachia relate health experiences as described by their nuclear and extended family members. The home is a significant locus in the production of both disease and wellness with older family members being role models for the health-related behaviors of younger members (Denham, Meyer, Toborg \& Mande, 2004).

Vinton County, located in western Appalachia, lies between the cities of Chillicothe to the west and Athens to the east. The county has a population of 13,435 , with $24.5 \%$ under 18 years old. The Vinton County land area is 
414.08 square miles with 32.4 persons per square mile. The median household income is $\$ 34,275$ (Quick Facts, 2011). Vinton County has no health care facility and limited health care resources available. Ninety-four percent of the elementary students are economically disadvantaged (Vinton County School System, 2011).

\section{Standards And Guidelines For Development Of Project}

Healthy People was developed in 1979 by the Surgeon General with the release of The Surgeon General's Report on Health Promotion and Disease Prevention (National Center for Health Statistics, 2010). The purpose of Healthy People was to reduce premature deaths and promote independence of older adults (National Center for Health Statistics, 2010). The overall goal was to promote the health of the U.S. population into groups of infants, children, adolescents and young adulthood, and adults and older adults (National Center for Health Statistics, 2010). The first goals for Healthy People were written for 2010 and the most recent goals are for 2020, which were used in this project.

The goals chosen for this project from Healthy People 2020 were 1) "create social and physical environments that promote good health and 2) promote quality of life, healthy development, and healthy behaviors across life stages" (IOM, 2011, p.3). The focus group for the project was children in elementary school Kindergarten through fifth grade. Topics and objectives used to meet these goals were developed on health promotion and quality of life pertaining to nutrition/exercise, bullying/conflict management, hygiene/dental and gun safety/fire (IOM, 2011).

The following standard of Accreditation Commission for Education in Nursing (ACEN; formerly National League for Nursing Accreditation Council [NLNAC]) Standards and Criteria for evaluating associate degree nursing programs, was also used to guide the project: Standard 1: Outcome 1.4 Partnerships exist that promote excellence in nursing education, enhance the profession, and benefit the community. (ACEN, 2008, p.81)

The ACEN is an organization whose purpose is to provide specialized accreditation for schools of nursing, which promotes self-improvement, equality and propagate standards in nursing programs (ACEN, 2008).

As stated previously, service learning, according to Balakas and Sparks (2010), is a teaching strategy that promotes it in the community and academic setting.

\section{Development And Implementation Of Project}

Characteristics of service learning include a plan, implementation, and collaborative evaluation with a community partner. This section focuses on the development and implementation of this service learning project utilizing these characteristics and using the following outline:

- $\quad$ Establishing a partnership with the school nurses in Vinton County

- $\quad$ Establishing guidelines for OUC student nurses

- Determining health needs and topics for education

- Implementation of project

During the planning phase, the Nursing Coordinator made the initial contact with the school nurses in Vinton County. Together they decided on nursing students educating the elementary students in their classrooms following set objectives.

The needs of a service learning project are identified by the community rather than the educators (Balakas $\&$ Sparks, 2010). The school nurses assessed the health needs of the kindergarten through fifth grade students and topics were given to the Nursing Coordinator. Health promotion topics included Hygiene, Nutrition/Exercise, Dental, Fire and Gun Safety, and Bullying/Conflict Management. 
Next, the Nursing Coordinator and clinical nursing faculty examined the course and clinical objectives for the project and determined guidelines for the nursing students. Among the objectives were:

- $\quad$ Provide the student with the opportunity to practice the application of the principles of teaching and learning

- $\quad$ Provide the student with observation of social interactions and assessment of age appropriate behaviors based on developmental theories

- $\quad$ Demonstrate the concepts of effective communication

- $\quad$ Apply principles and implement strategies relating to the teaching learning process

- $\quad$ Discuss health promotion topics to pre-identified audience

- $\quad$ Complete research on assigned topic

Finally, it was time for implementation. The topics and paper requirements were given to the nursing students by the fourth week of the semester. Groups of 3-4 students were assigned the health promotion topics. Students were required to develop and implement a teaching learning project for presentation to a classroom of elementary students. The teaching plan/paper was to be typed utilizing APA format. The typed portion of the paper was Phase 1 and the implementation/presentation of the project was Phase 2. Each group was required to develop an age appropriate poster of their topic and distribute at least one handout to each student to share with their family.

The Nursing Coordinator met with all student groups one week after the topics were assigned. During that meeting, students were informed of community resources that were available to be utilized in assisting them with ideas and goal development. Students were reminded that all members of the group were to communicate with each other and participate equally. Each group submitted their paper two weeks before the presentation to the Nursing Coordinator.

A sign-up form with topics and presentation times was sent to the schools on the fourth week of the semester. Each teacher had the opportunity to sign up for the topics of choice for their class. The completed schedule was given to the nursing students one week prior to the presentations. This enabled the students to know what grades they would be teaching throughout the day. Each student group developed a twenty minute presentation for each classroom and taught at least eight classes.

\section{Evaluation Of Project}

The success of this service learning project depended on the successful collaboration between the college and elementary schools. The service learning project benefited both collaborating partners through sharing of knowledge, expertise and skills.

Some of the student and college benefits were:

- $\quad$ Curriculum integration - connecting the academic and clinical content to the community partnership

- Utilization of community resources

- Increased confidence and leadership abilities

- Interactions with children in grades Kindergarten through fifth grade

- $\quad$ Team Building - students learned how to work well with other students

Benefits for the community partners, Appalachian schools, were:

- $\quad$ Provided health education to students in a rural area

- $\quad$ Distributed topic handouts to all students and additional resources to each teacher

- $\quad$ Referred students if indicated in relation to health promotion topics

An evaluation was completed by each student. Ninety-eight percent of all students' evaluations felt this was a valuable assignment to utilize teaching learning principles in the elementary classroom of an Appalachian 
community. All students verbalized that the education provided to the elementary students may influence the way they think about their health. Consequently, service learning participation was a predictor of increased student learning outcomes.

\section{CONCLUSION}

In this area of Appalachia, a service learning approach to providing health education in a unique clinical setting is an excellent way to inform children of health practices that lead to healthy lifestyles. It is also a valuable experience for the nursing students to apply the didactic content to an actual "real-life" situation. This approach to teaching is a win-win situation for each of the collaborating partners.

\section{AUTHOR INFORMATION}

Lisa Kauffman-Craig, RN, MSN, CNE, is a Visiting Professor for Chamberlain College of Nursing, RN to BSN College and A.D. faculty, Bay Community College, Escanaba, Michigan. Kauffman-Craig recently retired from the OU system after 18 years of service to the nursing program. Her primary area of teaching included medical/surgical nursing and nursing assessment. She also served as the liaison for the Berger nursing site for five years. KauffmanCraig's main area of research interest includes community, partnerships and service learning. Other areas of interest include education/teaching strategies in the clinical and classroom setting. Lisa received her certification in nursing education in 2010, a prestigious award granted by the National League for Nursing. Email: lisa.craig@ BayColledge.edu.

Charlotte McManus, RN, MSN, is a full-time assistant professor with the A.D. Nursing Program of Ohio University. She has served as the Associate Director of the A.D. Nursing for seven years. McManus has worked in the OU system for 21 years in the nursing program. Her primary areas of teaching include communication and foundations of nursing, LPN to RN Program, and Integrated Nursing Practice of senior students. McManus' area of research interest includes community partnerships and service learning. Charlotte has collaborated with schools, industry, correctional facilities and extended care facilities for health care seminars. She serves on the Health and Wellness Committee at OUC and served on the OUC Ethics committee. Email: mcmanusc@ohio.edu.

Vicky K. Parker, RN, PhD, FNP-BC, is an assistant professor and Regional Coordinator for the Bachelor of Health Services Administration of the Regional Campuses of Ohio University. Parker recently left the OU nursing program after 18 years of service. She is an actively practicing nurse practitioner in a rural family practice clinic. Her Bachelor of Science in Nursing is from Ohio University, Athens, Ohio. She holds two Masters Degrees from Wright State University - one in nursing administration/ community health and the other in family nurse practitioner. She received her $\mathrm{PhD}$ degree from Capella University, Minneapolis, Minnesota, in health care administration. Her research interests include use of technology and simulation as teaching strategies, rural community health care and primary care in rural populations. Email: parkerv@ohio.edu.

\section{REFERENCES}

1. ACEN [Accreditation Commission for Education in Nursing, formerly the NLNAC]. (2008). Accreditation Manual 2008 Edition. Retrieved from http://acenursing.org/.

2. Bakalas, K. \& Sparks, L. (2010). Teaching research and evidence-based practice using a serviceApproach. Journal of Nursing Education, 49(12), 691-695.

3. Commission on Collegiate Nursing Education [CCNE]. Standards for Accreditation of Baccalaureate and Graduate Nursing Programs. (Amended 2013). http://www.aacn.nche.edu/ccne-accreditation.

4. Denham, S., Meyer, M., Toborg, M., \& Mande, M. (2004). Providing health education to Appalachia populations. Holistic Nursing Practice, 18(6), 293-301.

5. IOM (Institute of Medicine). (2011). Leading Health Indicators for Healthy People 2020: Letter Report. Washington, DC: The National Academies Press.

6. National Center for Health Statistics. Healthy People 2010 Final Review. Hyattsville, Maryland: Public Health Service. (2010). Library of Congress

7. Ohio University-Chillicothe. (2011). Ohio University-Chillicothe. Retrieved from 
http://www.chillicothe.ohiou.edu/.

8. $\quad$ Quick Facts: Vinton County, Ohio. (2011). Retrieved from http:

www.quickfats.census.gov/gfd/states/39/39163.html.

9. Robinson, G. (2010). Community colleges broadening horizons through service learning, 2009-2012.

American Association of Community Colleges, PB-10-1, 1-3.

10. Vinton County Annual School Report. (2011). Vinton County Annual School Report 2011 